\title{
Doutrina da Proteção Integral e o Sistema de Garantia de Direitos de Crianças e fidolescentes
}

\author{
La Doctrina de Protección Integral y el Sistema de Garantía de Derechos \\ de niños y fidolescentes \\ The full Protection Doctrine and the System for Guaranteeing Rights \\ of Children and fidolescents
}

\author{
Eduardo Chaves* \\ Liana Fortunato Costa* \\ Universidade de Brasília, Brasília, Brasil.
}

Doi: http://dx.doi.org/10.12804/revistas.urosario.edu.co/apl/a.4092

\section{Resumo}

Este estudo tem como objeto analisar a ação dos operadores do Sistema de Garantia de Direitos de crianças e adolescentes em situação de violência sexual em relação à Doutrina da Proteção Integral, tal como surge no processo judicial. Foram realizados estudo de caso instrumental e análise documental com o intuito de conhecer os procedimentos técnicos do processo, assim como a percepção dos operadores do direito em relação à família e ao autor da violência atendidos pela Justiça. Foi constatado que a atuação do judiciário se pauta na garantia estrita do pilar de defesa dos direitos da infância, dentro do Sistema de Garantia de Direitos, mas se configura como pouco disponível ao diálogo com a sociedade no que tange à convergência de suas ações às reais e concretas necessidades dos sujeitos, o que demanda uma maior compreensão e convergência aos pilares da promoção/prevenção e controle social para que se possa observar a Doutrina da Proteção Integral e a Prioridade Absoluta da infância efetivamente instaurada nos processos de Justiça.

Palavras-chave: doutrina da proteção integral, psicologia jurídica, direito da criança e do adolescente, estatuto da criança e do adolescente.

\section{Resumen}

Este estudio tiene como objetivo analizar la acción de los operadores del Sistema de Garantía de Derechos de Niños y Adolescentes en Situación de Violencia Sexual en relación con la Doctrina de la Protección Integral, tal como surge en el proceso judicial. Se realizaron estudios de caso instrumental y análisis documental para

* Eduardo Chaves, Liana Fortunato Costa, Universidade de Brasília, Brasília, Brasil.

Correspondência a respeito deste artigo deve ser endereçada para Eduardo Chaves, Caixa Postal 6297 - Agência 508 Norte. CEP:

70749970. Correio eletrônico: educhaves.unb@gmail.com

Cómo citar este artículo: Chaves, E. \& Fortunato Costa, L. (2018). Doutrina da Proteção Integral e o Sistema de Garantia de Direitos de Crianças e Adolescentes. Avances en Psicología Latinoamericana, 36(3), 477-491. DoI: http://dx.doi.org/10.12804/ revistas.urosario.edu.co/apl/a.4092 
conocer los procedimientos técnicos del proceso y la percepción de los operadores del derecho en relación con la familia y el autor de la violencia atendidos por la justicia. Se constató que la actuación del judiciario se basa en la garantía estricta del pilar de defensa de los derechos de infancia dentro del Sistema de Garantía de Derechos, pero se configura como poco disponible al diálogo con la sociedad en lo que se refiere a la convergencia de sus acciones con las reales y las necesidades concretas de los sujetos, lo que demanda una mayor comprensión y convergencia con los pilares de la promoción/prevención y control social para que se pueda observar la Doctrina de la Protección Integral y la prioridad absoluta de la infancia efectivamente instaurada en los procesos de justicia.

Palabras clave: doctrina de la protección integral, psicología jurídica, derecho del niño y del adolescente, estatuto del niño y del adolescente.

\section{fbstract}

This study aims at analyzing the action of law professionals responsible for enforcing the System for Guaranteeing Rights of children and adolescents in situations of sexual violence in relation to the Doctrine of Full Protection, as it appears in lawsuits. An instrumental case study and a document analysis were performed, for the technical procedures of the lawsuit as well as the perception of law enforcement professionals in relation to the family and the perpetrator of violence assisted by the courts to be known. It was found that the judiciary performance is based on the strict guarantee of the pillar of defense of children's rights within the Rights Guarantee System, but is not very open to dialogue with society as regards the convergence of its actions with the actual and concrete needs of individuals, thus requiring greater understanding of and convergence with the pillars of promotion/prevention and social control, so that the Doctrine of Full Protection can be complied with and the Absolute Priority of childhood can be effectively established in judicial proceedings.
Keywords: Doctrine of full protection, judicial psychology, rights of children and adolescents, statute of the child and adolescent.

A proposta deste texto se situa no lócus de intervenção, no qual a família, a sociedade e o Estado atuam em conjunto no enfrentamento das violações de direitos contra crianças e adolescentes. Trata-se de resgatar o real e concreto ideal de empoderamento familiar, garantir direitos socialmente conquistados e, principalmente, responder substancialmente ao abuso sexual com uma intervenção pautada na não-violência.

Para tanto, toma-se como objeto de estudo o afastamento do agressor do lar em decorrência de denúncia de abuso sexual contra criança ou adolescente. Por meio de um estudo de caso, busca-se analisar o enfrentamento desta forma de violência a partir da atuação de um órgão importante do Poder Judiciário e sua inserção no sistema de garantia de direitos e a quebra da impunidade (Sauerbronn, n.d.).

Portanto, esse texto trata de um tema de interface entre a Psicologia e o Direito, central para a compreensão do fenômeno em sua totalidade. $\mathrm{O}$ tema da proteção à vítima nas situações de violência sexual intrafamiliar interessa a ambas as áreas de conhecimento, pois ressalta os aspectos da subjetividade presentes na dinâmica abusiva e evidencia as reações dos atores do judiciário, por meio das medidas de proteção decretadas.

Desde as últimas décadas do século passado, e nestes primeiros anos do novo milênio, a legislação brasileira - seguindo tendência mundial e devido a pressões internas advindas principalmente dos movimentos sociais - vem gradativamente passando por um processo de revisão e transformação no que se refere ao entendimento e tratamento das distintas violências contra crianças e adolescentes (Baía, Magalhães \& Veloso, 2014; Luna, Ferreira \& Vieira, 2010). O Estatuto da Criança e do Adolescente - ECA- (Brasil, 1990) representa, 
juntamente com a Constituição Federal (Brasil, 1988), o mais significativo marco legal nacional de defesa dos direitos da criança e adolescente, regulamentando as diretrizes constitucionais de proteção e defesa destes grupos.

A Doutrina de Proteção Integral, preconizada pelo Estatuto da Criança e do Adolescente (Brasil, 1990), e em especial seu Artigo $5^{\circ}$, que trata do tema da proteção, será o marco fundante deste texto, servindo de norte para os constructos advindos da articulação com outros apostes legais, como o Plano Nacional de Enfrentamento da Violência Sexual contra Crianças e Adolescentes (Brasil, 2013), Plano Nacional dos Direitos Humanos (Brasil, 2009), dentre outros. Dessa forma, parte-se do pensamento teórico-metodológico que vislumbra a violência como uma totalidade concreta, com mediações e peculiaridades historicamente correlacionadas que tendem a reproduzir tanto sua dinâmica e estrutura, quanto a possibilidade de negação das manifestações da violência enquanto quebra de direitos socialmente conquistados.

\section{Da Violência à Proteção de Crianças e Adolescentes}

O abuso sexual contra crianças é considerado um grave problema de saúde pública, pois tem manifestações complexas referentes ao desenvolvimento individual, familiar e comunitário da vítima. Aliado a isso, o enfrentamento do fenômeno também perpassa a mobilização de toda uma rede social, tanto de cunho jurídico-penal, quanto de proteção e promoção da saúde sexual dos indivíduos. Nesse sentido, normativas e serviços de atendimento têm sido formulados e implementados no Brasil, a exemplo do Plano Nacional de Enfrentamento da Violência Sexual contra Crianças e Adolescentes (2013), do Guia escolar: Identificação de sinais de abuso e exploração sexual de crianças e adolescentes (2011), dentre outros. Entretanto, o abuso sexual infantil se destaca de outras formas de maus-tratos infantis pela sua manifestação pouco focal em termos de prevenção, justamente por dificultar a atuação preventiva por seu caráter ilegal, clandestino e majoritariamente doméstico (Hohendorff, Habigzang \& Koller, 2015; Ferreira \& Azambuja, 2011; Santos \& Ippolito, 2011).

O Estatuto da Criança e do Adolescente instaurou a Doutrina da Proteção Integral às crianças e adolescentes, elevando-os de uma condição abjeta em termos de direitos sociais, a um patamar de sujeitos de direitos, que resguardadas suas peculiaridades, devem ter atendidas todas suas necessidades para um pleno desenvolvimento de suas potencialidades (Rizzini, 2008).

Entretanto, cabe ressaltar que essa transição de abjeção à condição de sujeito de direitos não foi simples. Os movimentos sociais de defesa da infância e adolescência travaram uma luta que não terminou com a simples negação da abjeção desses sujeitos, mas que também não permitia a atuação do poder público considerando essa parcela da população como objeto de intervenção, corroborando assim com a chamada Doutrina da Situação Irregular, balizada pelo Código de Menores de 1979. Dessa forma, foi necessária uma compreensão para além do repúdio à barbárie que permitisse dar novo significado à percepção social sobre a criança e o adolescente (Rizzini \& Pilotti, 2009).

Em pesquisa realizada em cinco cidades brasileiras de cinco regiões do país, coordenada por Faleiros e Faleiros (2006), há a constatação que a maioria dos abusadores é composta por familiares $(60.4 \%)$ ou ligados a familiares e conhecidos (33.3\%), na qual a convivência era muito próxima das vítimas, totalizando $93.7 \%$. Já em pesquisa conduzida por Habigzang, Ramos e Koller (2011), em $100 \%$ dos casos havia algum tipo de relação prévia do agressor com a vítima, mesmo em situações de violência caracterizadas como extrafamiliares. Esses dados mostram a dificuldade no enfrentamento de crimes sexuais no Brasil. Além disso, o discurso dos envolvidos no ciclo de violência ainda é o de desqualificação do ocorrido. 
Os agressores são vistos como cidadãos íntegros e os direitos das crianças agredidas sucumbem aos anseios da sociedade por um modelo de família linear e sem maiores conflitos. Essa análise ganha força quando consideramos a ocorrência de abuso sexual de forma velada, muitas vezes sem o uso de força física, pois o agressor possui estratégias próprias de persuasão, com falas peculiares e atos discretos. Nesse sentido, o ato legal é dificultado por considerar apenas como prova o testemunho das pessoas envolvidas, pois não há evidências objetivas em muitos dos casos (Pincolini \& Hutz, 2014).

Aliada à condição atual da infância e adolescência em situação de violações de direitos, como a violência sexual, infere-se que tanto Estado e sociedade, quanto a própria família, têm mostrado dificuldades em materializar a prioridade absoluta. Isso porque a condição peculiar de desenvolvimento que se encontra a criança e o adolescente é duplamente escamoteada quando referente à priorização absoluta, uma vez que essa condição especial as deixa em situação de vulnerabilidade e as coloca em posição menos favorável para exercer suas potencialidades e, consequentemente, a defender seus direitos (Machado, 2003).

Essa perspectiva aproxima a Doutrina da Proteção Integral e da prioridade absoluta da infância e adolescência ao cotidiano dos sujeitos, uma vez que articula tanto a ideia de atenção social básica (por meio de políticas públicas de assistência social integrantes da proteção integral), quanto a consideração de que as características constitutivas, motoras, endócrinas, psíquicas, intelectuais (cognitivas), morais e sociais das crianças e adolescentes são diferenciadas das de pessoas adultas (Machado, 2003). Esse entendimento ressignifica a necessidade de haver legislação específica para esse segmento da população, a fim de melhor considerar as questões individuais desses sujeitos, desde a primeira infância à adolescência, que são significativamente diferentes das neces- sidades de pessoas adultas (Victora, 2016; Senna \& Dessen, 2012).

Destarte, espera-se que este artigo contribua para a compreensão e enfrentamento da violência sexual contra crianças e adolescentes em uma perspectiva crítica acerca da relação interdisciplinar demandada pela Doutrina da Proteção Integral para a garantia dos direitos dessa população. Um olhar sensível por parte de todos os profissionais envolvidos no Sistema de Garantia de Direitos é imperativo, considerando que a defesa de crianças e adolescentes perpassa tanto a prevenção e o resgate da proteção da vítima e da família, quanto a responsabilização do agressor.

\section{Método}

Contexto - A pesquisa foi realizada no Centro de Referência para Proteção Integral da Criança e do Adolescente da Vara da Infância e da Juventude do Distrito Federal, do Tribunal de Justiça do Distrito Federal e Territórios — VIJ/TJDFT—, Brasil. Trata-se de um estudo de caso que pretende analisar com maior profundidade as várias dimensões contidas em processo de natureza complexa (Flick, 2009). O método de investigação escolhido foi a pesquisa documental que, em situações extremas de acesso ao sujeito podem representar as dimensões de risco e proteção (Flick, 2009). Optou-se por esse modo de acesso ao caso em virtude do objetivo precípuo de não revitimizar a família, por conta das várias entrevistas que a mesma já tinha se submetido (Potter \& Hoffmeister, 2016). O documento principal, fonte das informações, foi o estudo técnico realizado dentro do âmbito da VIJ/DFT.

Sujeitos - A família foi escolhida para a pesquisa por duas razões: por já ter sido feito um estudo técnico pelo Setor Psicossocial da VIJ/TJDFT, e por esse estudo conter uma determinação de medida protetiva constante no Art. 130 do Estatuto da Criança e do Adolescente, a saber, afastamento do agressor do lar comum. Trata-se, portanto, de 
amostra de conveniência (Flick, 2009). A família retratada no processo é composta da vítima Bianca (16 anos), suas irmãs Aline e Adriana ( 9 anos e 12 anos respectivamente), a mãe Renata (35 anos) e Caetano (38 anos), padrasto de Bianca e pai de Aline e Adriana. Os nomes são fictícios. O processo judicial iniciou-se em abril de 2008, quando houve denúncia formal, pela mãe, registrada junto à delegacia especializada em proteção. O caso foi encaminhado para a vara com descrição detalhada da violência sexual ocorrida, desde menção aos tipos de atos sexuais envolvidos, até as dinâmicas e situações que favoreciam a ocorrência dos abusos. $\mathrm{O}$ afastamento do suposto agressor do lar foi determinado imediatamente pelo juiz da Vara.

Bianca é filha de Renata e enteada de Caetano. Renata e Caetano têm duas filhas. Por volta dos doze anos, Bianca começou a ser abusada sexualmente pelo padrasto, o que ocorria com grande frequência. Caetano entendia como oportuna a ausência da esposa para praticar os atos abusivos, descritos por Bianca como por meio de retirada de suas roupas da cintura para baixo e toques e beijos em sua vagina, seios, boca e nádegas, sem que, no entanto, ela fosse obrigada a praticar felação ou houvesse penetração. A fim de viabilizar as práticas abusivas, Caetano oferecia dinheiro e presentes, como roupas e sapatos caros, além de permitir que ela saísse com mais liberdade que as irmãs. Bianca, apesar do desconforto com a situação, não relatava os abusos à mãe, pois tinha medo de que o casal se separasse caso a violência viesse à tona. Conforme Bianca ia entrando na adolescência, Caetano começou a mudar sua postura em relação a ela, aumentando a vigilância e atitudes de ciúmes, dando cada vez menos liberdade como fazia antigamente e a proibindo de namorar ou ir sozinha à escola ou a qualquer outro lugar. Em uma ocasião, Caetano dirigiu-se à escola pedindo ao diretor que vigiasse Bianca. Essa situação foi a oportunidade para a denúncia do abuso sexual que Bianca vinha sofrendo. A mãe foi contatada e se dirigiu ao Conselho Tutelar da cidade para efetuar a notificação da violência. Após a investigação foi decretada a medida de afastamento do agressor do lar, Caetano foi morar na residência do irmão Adilson e sua esposa Ivana, além das duas filhas deste casal, Kátia e Katarina.

Instrumentos e Procedimento de Coleta - Enfocaram-se o relatório de avaliação psicossocial, produzido pelo Setor Psicossocial da VIJ/DFT, e o processo jurídico correspondente, como fontes de retirada das informações. Detalhadamente, foram três os documentos pesquisados: um primeiro relatório apresentando a primeira análise técnica do setor psicossocial, um segundo relatório remetendo à condição da família e do agressor ao final de dois anos de acompanhamento, e o processo jurídico propriamente dito. O procedimento executado foi a cópia à mão, pois os documentos não podem ser retirados do Setor.

Procedimento de análise das informações - Para o processamento das informações, construiu-se uma planilha que reuniu as informações sobre os membros da família em estudo e sobre a sequência de decisões tomadas no âmbito jurídico, a fim de se criar um corpus de modo a possibilitar as interconexões entre as informações obtidas (Flick, 2009). Os itens constantes dessa planilha foram: descrição do abuso sexual sofrido; dinâmica familiar; procedimentos realizados; voz da vítima; voz do agressor; descrição dos sentimentos dos sujeitos; posição de proteção à vítima adotada pelos profissionais; decisões do juiz. A seguir, as informações foram analisadas na perspectiva da Análise Temática de Minayo (1993), que inclui quatro etapas: uma leitura inicial flutuante; a captação de significados dados às informações; a reunião de sentidos comuns a esses significados; e a construção de eixos de discussão que são compostos pela interpretação dos conteúdos apreendidos.

Cuidados Éticos - Primeiramente, o Exmo. Sr. Juiz da $1^{\text {a }}$ Vara da Infância e Juventude do Tribunal de Justiça do Distrito Federal e Territórios concedeu autorização para realização do trabalho 
em 25 de janeiro de 2010. O projeto foi submetido ao Comitê de Ética em Pesquisa do Instituto de Ciência Humanas da Universidade de Brasília (IH/UnB), Brasília, Brasil, e aprovado na data de 04 de maio de 2010.

\section{Resultados e Discussão}

\section{Da Proteção (Re)Estabelecida à Garantia de Direitos?}

Após a leitura dos relatórios e do processo, e o preenchimento da planilha, uma leitura exaustiva de todas as informações permitiu a construção de eixos de discussão que serão apresentados a seguir:

A proteção devida - A proteção da infância e adolescência é entendida como fundamental para o desenvolvimento da autonomia e da personalidade do indivíduo (Marra \& Costa, 2016). Conforme debatido a seguir, a transposição de sentimentos, falas, gestos, silêncios, recusas, lágrimas e demais singularidades humanas têm que ser reduzidas a termos cabíveis juridicamente como pertinentes ao fazer jurídico. A centralidade dos objetivos das ações protetivas do processo judicial é mais bem observada a partir da leitura de relatórios técnicos, que além de expressarem a visão acurada de equipe capacitada para lidar com o tema, acaba por se tornar também a própria voz do Ministério Público, que corrobora quase sempre com as sugestões destes relatórios. Estes relatórios são o fio condutor da representação dos sujeitos enquanto pessoas, visto que questões subjetivas e individuais não são totalmente consideradas pelos textos das diversas normativas legais que tratam do tema.

Ao se observar o trato dado pelo caráter multiprofissional do processo judicial, ainda que a caneta do magistrado tenha a tinta mais forte, os relatórios técnicos evidenciaram que a medida de afastamento foi manejada de forma a permitir que muitas inferências, sentimentos, atos e relatos fossem explicitados no decorrer de sua execução. No que concerne à análise das manifestações em processo da convergência da medida de afastamento e as implicações psicossociais, a voz da vítima esteve presente desde o relato ao diretor, passando pela ciência da mãe, do Conselho Tutelar, do sistema policial e, finalmente, pela justiça, especialmente a partir de técnicas de atendimento específicas da equipe psicossocial, que permitiram à vítima se expressar da forma mais espontânea possível. Ainda que houvesse atenção sensível à fala do agressor e inferências sobre os demais membros da família, a centralidade da atenção psicossocial foi, de fato, a vítima.

Para que a referida Doutrina da Proteção Integral seja materializada na vida de famílias em situação de violência e a efetiva proteção integral de suas crianças ou adolescentes vítimas, é preciso que haja articulação de diversos agentes operadores do direito infanto-juvenil. No entanto, o processo fez um recorte no que tange a uma atuação mais ampla de outros agentes, que passaram à margem do processo. É importante ressaltar que o processo cível privilegia as ações do judiciário ou as estimuladas por ele, o que demonstra que uma ação de proteção pode ser tomada sem a participação do Poder Judiciário.

Nesse sentido, notou-se que a ação do Estado para resgatar a proteção envolveu vários agentes, como a escola, Conselho Tutelar, Delegacia, Ministério Público, Vara da Infância, Secretaria de Saúde e instituições do terceiro setor. Em relação à escola, seu papel foi fundamental como motivador da denúncia, pois a dinâmica familiar de segredo e triangulação amorosa entre Caetano, Bianca e Renata só foi rompida com a inclusão de um novo elemento para atenuar o sofrimento da vítima, ao compartilhar da situação vivida pela família. Dessa forma, foi possível uma interferência no arranjo familiar que visava, em última análise, proteger o sistema de rompimento (Minuchin, Nichols \& Lee, 2009).

A escola se mostra um importante agente de prevenção e garantia de direitos, justamente por se tratar de uma política pública na qual a criança 
fica inserida durante um maior tempo. No Brasil isso ocorre, em média, por cinco horas diárias, em escolas públicas (Brasil, 2004). Assim, os educadores devem estar capacitados para lidar com questões dos alunos para além do âmbito ensino e aprendizagem, dada a impossível desvinculação de aspectos da vida cotidiana quando inseridos nas diversas instituições sociais (Habigzang \& Koller, 2011; Pereira \& Williams, 2012).

O diretor da escola, o primeiro agente público a tomar conhecimento do caso, exerceu sua obrigação prevista nos Art. 13 e 245 do ECA de forma a preservar a vítima de sofrer revitimização, pois procurou a mãe de Bianca para irem juntos ao Conselho Tutelar efetivar a notificação de maus-tratos, conforme preconiza o Estatuto da Criança e do Adolescente (Brasil, 1990). A sensibilidade e discrição com que o diretor se colocou perante a situação evitou, por exemplo, que se chegasse a uma decisão repentina de afastamento do lar, antes mesmo da mãe e do possível agressor tomarem conhecimento de sua publicização. E, além disso, poderia causar consequências subjetivas às outras filhas do casal (Brino \& Williams, 2009).

Entretanto, não há referências mais aprofundadas no processo a respeito de possíveis consequências da revelação do abuso ou de questões relativas ao âmbito do ensino e aprendizagem, com relação à Bianca, ainda que a escola tenha exercido seu papel no resgate da proteção ao ensejar a denúncia. Uma vez que as consequências da medida protetiva não foram aprofundadas a ponto de aparecerem como parte importante da sociabilidade da vítima, a partir de possíveis desdobramentos do abuso e da medida em âmbito escolar, esse contexto acaba por infirmar o papel da escola como agente responsável pela proteção integral de seus alunos (Oliveira, Costa, Amaral, Santos, Assis \& Nascimento, 2014).

Não admira, portanto, que a relação estabelecida entre a família e a delegacia tenha sido um híbrido de proteção e desqualificação da violência enquanto produtora de sentimentos e consequên- cias subjetivas para além da apuração criminal. Embora tenha sido célere em seus procedimentos (encaminhamento do caso para o juiz da infância e indiciamento do agressor), a delegacia indica a adoção de medidas protetivas específicas em razão da vontade, expressa em depoimento, da genitora da vítima, Sra. Renata, em continuar o convívio familiar com a filha e o marido, Sr. Caetano, suposto agressor e padrasto de Bianca. Aqui, aparecem aspectos relevantes. $\mathrm{O}$ primeiro diz respeito à sugestão específica dos incisos II e III do Art. 98 do Estatuto da Criança e do Adolescente - ECA, que mencionam: “Art. 98: as medidas de proteção à criança e ao adolescente são aplicáveis sempre que os direitos reconhecidos nesta Lei forem ameaçados ou violados: [...] II - por falta, omissão ou abuso dos pais ou responsáveis; III - em razão de sua conduta".

A indicação ao inciso II do supracitado artigo é precisa ao confirmar a falta, omissão ou abuso do(s) responsável(is), já que a denúncia recaía contra o padrasto. Mas a assertiva da mãe em continuar com o marido sob o mesmo teto da filha indica que a intenção da delegacia era afirmar a "falta ou omissão" por parte da mãe, pois nesse entendimento ficou evidente a continuidade da situação de risco vivida por Bianca. Já o inciso III demonstra uma preocupação moral para com a existência da suposta violência. Isso porque os incisos I (por ação ou omissão da sociedade ou do Estado - que, na ótica da representação da delegacia não se aplica ao caso em tela) e II configuram a quebra de direitos presentes na legislação de forma universal (direito à vida, educação, lazer, saúde, convivência familiar e comunitária), sendo assegurados à infância e adolescência de forma prioritária.

Uma vez que o inciso III elenca que uma medida de proteção pode ser aplicada também em razão da conduta da própria vítima, sua inclusão por parte da delegacia de proteção como justificativa no inquérito infere que a vítima do abuso foi corresponsável por sua ocorrência, visto que não 
foi mencionada explicitamente a falta, omissão ou abuso de outras pessoas envolvidas ou não na denúncia. Ainda que o entendimento jurídico para a inclusão desse inciso em uma medida de proteção seja assegurar a "presunção de violência", uma vez que a criança ou adolescente não teria condições de discernir sobre as ações de outrem ou até mesmo suas próprias condutas, percebe-se que há a certa culpabilização da vítima pela ocorrência do abuso, uma vez que não se pode admitir corresponsabilidade nesse tipo de violência.

Em suma, os documentos pesquisados revelam que a proteção, a despeito de alguma imprecisão, é decretada e se concretiza na vida prática, interrompendo a violência sexual.

A ação protetiva dos operadores do Direito - A medida de afastamento foi imediatamente aplicada pelo Juiz da Vara da Infância, reiterando a pena de três meses a dois anos de detenção em caso do suposto agressor. O magistrado determinou também que a genitora da vítima não poderia permitir que o padrasto viesse a ter contato com a enteada, mas não fez menção ao crime de desobediência, caso ela não cumprisse a determinação. Esta postura do juiz demonstra a divergência ao posicionamento da delegacia, que encaminhou a família àquela vara, ao fundamentar tal decisão na omissão da mãe, assim como cita o Artigo 98, II, do Estatuto da Criança e do Adolescente.

A atuação do Ministério Público é importante no sentido de possibilitar a quebra da rigidez positiva da lei, ao solicitar antecipação da tutela quanto ao afastamento (assegurar a guarda e responsabilidade à mãe em razão do afastamento do agressor), além de avaliação técnica das correspondências trocadas entre Caetano e as filhas. O Ministério Público abriu possibilidade de reversão da medida de afastamento, posteriormente refutada parcialmente pelo segundo estudo técnico psicossocial. Dessa forma, é pertinente frisar que o Ministério Público aparece no processo judicial, na maior parte das vezes, corroborando as sugestões contidas nos relatórios técnicos realizados pela equipe do setor psicossocial, o que demonstra, de certa forma, que a análise dos relatórios nos remete a compreensão da postura do Ministério Público, alargando a discussão a respeito do tema (Ferreira, 2012). Nas diferentes abordagens dadas por meio das ações de justiça, que se configuram o alicerce para o efetivo exercício dos direitos dos sujeitos envolvidos no processo, percebe-se também certa indistinção das medidas de proteção em relação a que agente social compete viabilizar na prática a proteção. Isso fica evidente na medida em que a ação da avaliação realizada pelo setor psicossocial tem alcance terapêutico para além da avaliação técnica requerida pelo juiz da Vara.

O trabalho do assistente social e do psicólogo na justiça, como assessoramento às decisões do magistrado, lida com a falta de demanda espontânea dos sujeitos e a dualidade inerente à obrigatoriedade do tratamento inserido dentro da decretação da pena. A decisão judicial com um caráter terapêutico decorre da aplicação dos preceitos legais fazendo com que a ação do setor psicossocial da Vara da Infância seja um lócus de intensa correlação de forças (Vertamatti, Abreu, Drezetti, Valenti \& Barbosa, 2013).

Os atendimentos aos sujeitos (vítima, agressor e genitora), por si só já configuram o contexto relatado acima, mas ainda são necessários a fim de que seja possível uma avaliação sobre qual ação de proteção é a melhor para o caso naquele momento. Observou-se que o trânsito entre as ações propostas pelo setor psicossocial, e aceitas pelo Juiz no sentido de viabilizar a garantia de direitos, é claudicante desde o princípio, especialmente quando a relação com a rede de proteção social da cidade se mostra desarticulada entre si (Sauerbronn, n.d.).

As ações para além dos atendimentos realizados na Vara da Infância para fomentarem o parecer psicossocial foram encaminhamentos para instituições que prestam serviços socioassistenciais. Vítima e genitora foram atendidas por uma instituição que presta atendimento de saúde. Ambas ficaram muito satisfeitas com os serviços odontológicos 
prestados. Elas também foram encaminhadas à instituição que presta atendimento psicológico, porém não foram atendidas por falta de vaga disponível. Já o agressor foi encaminhado para atendimento em uma instituição de atendimento psicológico, mas até a conclusão do processo, em função de sua indecisão em aderir ou não aos atendimentos propostos pela equipe da Vara da Infância, não havia comparecido aos chamados.

Estes paradoxos e contradições demonstram que foi possível ao juiz, com base na avaliação e indicação do setor psicossocial, a aplicação de medidas protetivas para a vítima (Art. 101, inciso $\mathrm{V}$ - tratamento psicológico), para o agressor (manutenção da medida de afastamento concomitante a tratamento psicológico - Art. 129, III) e para a genitora (Art. 129, IV - encaminhamento a cursos ou programas de orientação), mesmo não havendo, até este momento, expressão de demanda por parte dos envolvidos para esses encaminhamentos. Em relação ao último ponto citado, a decisão do juiz data de 13 de março de 2009. Em 06 de maio de 2009, quase dois meses após a decisão judicial, a instituição oficiada para atendimento psicológico responde, por ofício, que há lista de espera, sendo uma possibilidade o encaminhamento de Bianca a outra instituição.

É possível presumir que a violência foi interrompida, como ficou demonstrado no item anterior. A ação dos operadores do Direito se efetua de forma concreta, viabilizando a proteção. Há uma clareza no processo e conexão com as necessidades da vítima e a observação da complexidade da situação. Entretanto, o que se mostra desconectada é a realidade de execução das medidas de proteção quando são repassadas às instituições da comunidade. Observa-se um descumprimento das decisões judiciais no que tange às ações das instituições que deveriam efetivamente oferecer as ações para potencializar a não volta da situação da violência sofrida (Santos \& Costa, 2011; Santos, Costa \& Silva, 2011).

A ação protetiva dos agentes sociais - Após a decretação das medidas de proteção, a família ficou em acompanhamento pela rede de instituições encarregada de executar as determinações do juiz. Essa fase do processo culminou em novo relatório técnico elaborado pelo setor psicossocial cujas sugestões de medida foram aceitas pelo magistrado. Cabe destaque, além da reiteração das medidas aplicadas na decisão anterior do juiz, a manutenção do afastamento com ressalva de possível alteração "condicionada ao encaminhamento de parecer técnico periódico sobre a evolução de seu tratamento [Art. 129, III], de forma a atestar a viabilidade da alteração ou revogação da medida de afastamento", a autorização para a realização de visitas supervisionadas de Caetano às filhas pela genitora, "condicionadas ao início do tratamento, a serem realizadas conforme sugerido pela equipe técnica", posteriormente sendo oficiada a instituição de atendimento psicoterápico.

O primeiro ponto a se levantar são as características das instituições mobilizadas para executarem as medidas protetivas sugeridas e aceitas pelo juiz. Apenas a instituição que faz parte do poder público não pode atender a demanda da família em razão de suposta falta de vagas. As demais instituições são representantes do chamado terceiro setor, que são organizações que surgiram por iniciativa dos próprios sujeitos à margem dos direitos sociais para que eles tivessem a possibilidade de lutar por esses direitos. Assim, nas diferentes instâncias de execução dos direitos dos sujeitos, observa-se que a descontinuidade das ações é fator de difícil trato pelos operadores do direito. Embora haja esforços no sentido de estreitar a relação entre Estado e sociedade no enfrentamento da violência sexual, conforme se observou no processo por meio da articulação com entidades do Estado e do terceiro setor, notou-se também que, ao não ser efetiva a ação direta do Estado na garantia de direitos dos sujeitos em estudo, a transferência das obrigações do poder público para a sociedade se materializou neste processo judicial. Isso foi observado a partir da relação entre a Vara da Infância e os parceiros da rede que demonstrou ter maior precisão e garantia 
de acesso quando em contato com instituições não-estatais (Faleiros, 2010).

O papel do Judiciário em relação a essas instituições parceiras, após o encaminhamento de algum caso para atendimento, deveria seguir a orientação do Art. 95 do Estatuto da Criança e do Adolescente, que preconiza a atribuição de fiscalização ao Judiciário, além do Ministério Público e o Conselho Tutelar (Brasil, 1990). No entanto, embora a legislação e a construção da ação democrática de garantia dos direitos da infância e da adolescência se embasem na cooperação entre os agentes operadores do direito, o processo em estudo evidenciou que a intensidade da ação terapêutica e de impacto reparador junto aos sujeitos, teve maior evidência nas ações do judiciário por meio de atendimentos psicossociais dentro da justiça.

Essa constatação corrobora também a iniciativa do setor psicossocial da Vara em incluir as irmãs adolescentes da vítima no processo judicial, pois o rigor da lei determina que Bianca tenha o processo encerrado em razão da completude da maioridade civil. Dessa forma, a desarticulação entre a rede de proteção social e a confusão dos papéis e atribuições institucionais agem também como dificultadoras da garantia dos direitos das pessoas em situação de violência sexual. Isso se deve ao fato de que as ações do Poder Judiciário cessam em determinado tempo de processo, conforme determina a lei, e isso acaba por afetar as atividades socioassistenciais de entidades do terceiro setor que perdem o apoio formal de órgãos do judiciário na continuidade dos atendimentos aos sujeitos. Assim, um maior cuidado com os sujeitos poderia ser adotado em caso de melhor definição de papéis e de continuidade da ação restaurativa para além da vinculação estrita dos sujeitos com a justiça, uma vez que os conflitos e consequências psicossociais não seguem as imposições da lei para se perpetuarem, tampouco para cessarem.

É importante mencionar que essa desarticulação é fator de entrave ao pleno funcionamento do Sistema de Garantia de Direitos da Criança e do
Adolescente. Basicamente, este sistema funciona em três eixos principais, a saber: promoção; defesa; e controle. Em relação ao judiciário, sua atuação se situa no âmbito da defesa, uma vez que é função deste poder a fiscalização das ações de atendimento e a responsabilização caso a atenção à infância não esteja de acordo com o que prevê o Estatuto da Criança e do Adolescente (Freitas, 2011).

Entretanto, os três eixos não podem fundamentar suas ações em atividades desarticuladas, pois a promoção de direitos, por meio de políticas públicas e sociais, e o controle social pela sociedade não se exercem em um sistema inativo ou inoperante (Faleiros \& Faleiros, 2006). Assim, este estudo demonstrou que a defesa dos direitos da infância e juventude tem certa eficácia, mas se mostra apologético no sentido de se sobressair aos demais eixos do Sistema de Garantia de Direitos, justamente por ser o eixo encarregado da responsabilização e conduzido pelo Poder Judiciário, que conforme discutido alhures, acaba por se reduzir a procedimentos com vistas à punição do agressor.

A aplicação da medida de afastamento do agressor do lar - $\mathrm{O}$ respaldo legal para justificar a aplicação da medida de afastamento não gerou extensividade às peculiaridades da família. Após o juiz tomar conhecimento do fato por meio de ofício da delegacia, dois pontos justificaram juridicamente a aplicação da medida de afastamento: a existência de atentado violento ao pudor praticado pelo padrasto; e a consideração da gravidade da violação aos direitos da jovem e presentes os requisitos do fumus bonis júris e periculum in mora, que se constituem respectivamente pela violação aos direitos fundamentais da adolescente - que se encontra na situação descrita no Art. 98, inciso II do Estatuto da criança e do Adolescente - e pela necessidade de uma rápida intervenção estatal, a fim de que a jovem e suas irmãs não continuem expostas à situação de risco.

A separação do agressor da vítima quando a denúncia de abuso sexual ocorre parece ser a decisão mais acertada, visto que não se tem conhecimento 
do potencial de perigo que a criança ou adolescente está submetida. Nesse caso, a saída do lar pode ser tanto da vítima, quanto do agressor, com peculiaridades em ambos os movimentos de preservação da vítima (Habigzang, Ramos \& Koller, 2011). Em primeiro lugar, a legislação para a infância no Brasil, balizada pelo Estatuto da criança e do Adolescente, assegura que a convivência familiar é condição para que a criança em situação de vulnerabilidade tenha seus direitos garantidos (Brasil, 1990). Em segundo lugar, retirar a criança do lar quando há suspeita de que seus direitos estão sendo violados, apenas acontece quando a família notadamente está em desorganização que causa danos a integridade de seus filhos. É evidente que qualquer diagnóstico familiar demanda certo tempo para a avaliação técnica mais fidedigna, justamente por isso que tem se adotado a medida de afastamento do agressor, e não da criança em casos de abuso sexual.

Sob a ótica das relações afetivas em uma família, o afastamento do agressor antes mesmo de condenação criminal é pensado com o entendimento de que o adulto deve tomar completa responsabilidade pelo abuso e as consequências sociais, morais e jurídicas de tal fato. Dessa forma, aliado ao fato de que no Brasil, de modo geral, as instituições de acolhimento de crianças não oferecem todas as condições necessárias para a garantia de direitos, a criança vítima é duplamente penalizada ao ter que deixar os laços familiares, suas atividades comunitárias e sociais (Siqueira, Zoltowski, Giordani, Otero \& Dell'Aglio, 2010).

No entanto, percebeu-se no decorrer do processo que a decisão inicial não privilegiou esse caráter reparador, tanto para vítima, quanto para o agressor, que advém de uma medida de afastamento. As consequências positivas limitaram-se, num primeiro momento, ao fim da possibilidade de novos abusos sexuais, possibilidade esta que findou por ser menos mencionada nos relatos dos sujeitos do que as consequências negativas da medida, a saber, sofrimento pela ausência do pai, medo de desamparo financeiro, prejuízo para os papéis sociais dos membros, etc. Quando Caetano contestou pela revogação da medida de afastamento, motivando estudo técnico a respeito, depreende-se que ele entendeu o afastamento como um susto, uma ameaça do sistema judiciário para a não tolerância desse tipo de conduta. Embora haja relatos pela literatura de que alguns agressores não enxergam o abuso como não aceitável (Esber, 2009; Schmickler, 2006), no caso em tela essa conduta já era percebida como não aceitável, dada a construção do segredo observada pelos relatos durante os quase quatro anos de abusos. Mesmo que o fim reparador tenha se manifestado por diversas vezes no decorrer do processo, esse entendimento deveria ser a centralidade da ação, pois Caetano pode ter tido o entendimento que era preciso responder por algo que a sociedade não aprova, reconhecendo assim o direito que esta tem em punir, não o abuso sexual cometido como um erro propriamente dito.

\section{Considerações Finais}

O encaminhamento da família para avaliação psicossocial possibilitou o alargamento da compreensão sobre o afastamento e tradução das vozes dos sujeitos. A avaliação técnica deste caso se focou em dois momentos principais. O primeiro, em relação à atuação dos parceiros da rede de atenção e garantia dos direitos da infância. O segundo, e mais determinante no processo judicial e de consequências mais diretas, diz respeito à avaliação da equipe do setor psicossocial como subsídio para as demais ações do Poder Judiciário e do Ministério Público.

No caso do primeiro aspecto mencionado, percebeu-se que ao estudo psicossocial que resultou no relatório técnico, se inseriram no processo judicial, questões atinentes aos sentimentos iniciais em relação à ausência da figura masculina de referência na família. Além disso, também retratou a ambivalência da mãe e da vítima para com todo 
o contexto que estavam vivendo e como isso influencia no cumprimento da medida de proteção. Observou-se que a ação terapêutica proporcionada pelos procedimentos da equipe psicossocial que elaborou o relatório técnico, foi pautada no fortalecimento dos vínculos familiares, sem, contudo, ignorar a nova dinâmica que foi permeada por novos segredos e a questão econômica gerada pelo afastamento. Foi importante a percepção de que houve reordenamentos na relação entre os membros, mas vínculo afetivo ambivalente, rotinas de segredo e dificuldades de comunicação se mantiveram antes e depois do abuso (Hohendorff et al., 2015; Marra \& Costa, 2016).

Importante mencionar que foi sugerido ao agressor tratamento específico para lidar com os impulsos sexuais, cuja efetividade foi praticamente nula. Isso se deveu ao fato de a rede de proteção social não estar preparada para atender os sujeitos de forma sistêmica, pois a declaração de demanda não garante automaticamente a adesão imediata ao tratamento, fato reforçado pelo não comparecimento de Caetano ao atendimento psicológico junto à rede de proteção. Tratou-se, portanto, de um sujeito que agrediu sexualmente e cujas características pessoais não convergem ao perfil típico de agressores sexuais - que normalmente negam o abuso, não assumem responsabilidade pelo ato e desqualificam a vítima -, mas mesmo assim não teve atendimento a sua demanda declarada por tratamento (Meneses, Stroher, Setubal, Wolff \& Costa, 2016).

Já a atuação da equipe psicossocial foi assertiva ao garantir os direitos da vítima e possibilitar que uma avaliação mais próxima possível do real dos sentimentos expressos pelas partes durante os atendimentos. Nesse sentido, um dos pontos chave foi a utilização de uma técnica, durante o processo de avaliação, que possibilitou uma expressão mais espontânea de Bianca. Autilização desse instrumental pode legitimar que Bianca fosse escutada, como já o fizera por diversas vezes, desde que relatou o abuso ao diretor de sua escola (Santos et al., 2011).
Este instrumental também permitiu a reflexão de Bianca quanto à trajetória vivida por ela antes e depois da revelação do abuso, assim como aludir à forma que ela percebe os demais membros da família. A intervenção profissional, ao conseguir obter respostas da vítima, reduziu os efeitos que a vergonha sentida em decorrência do abuso e a consequente desestruturação da família se tornasse um padrão quando o assunto era sua família.

Observou-se também que a fala da vítima e da mãe foi traduzida a ponto de ser considerada parte fundamental e fundante do relatório técnico, uma vez que o referido documento fez ponderações que consideraram as especificidades da dinâmica familiar para tecer suas sugestões ao magistrado e também fomentaram a participação de ambas no processo de restauração da saúde afetiva da família de maneira mais ativa, como em reflexões durante os atendimentos na Vara e a adesão aos serviços da rede de proteção. Esse aspecto, assim como previamente sugerido pela equipe psicossocial da instituição parceira, abre espaço para a efetividade do empoderamento familiar após o percurso trilhado na justiça, aumentando as chances de trabalhos terapêuticos específicos com o núcleo familiar fora do ambiente jurídico (Marra \& Costa, 2016).

Ainda nesse contexto, quando o agressor se manifestou com postura de reconhecer suas responsabilidades, o parecer técnico psicossocial assumiu uma posição intransigente na defesa dos direitos da vítima. Isso se deveu ao fato de que, mesmo percebendo o movimento restaurador do autor, não sugeriu a suspensão da medida de afastamento. Quando muito, após quase dois anos do início do processo, o parecer técnico sugeriu que o juiz permitisse visitas supervisionadas condicionadas ao efetivo cumprimento da medida protetiva prevista no Art. 129, inciso III do Estatuto da Criança e do Adolescente, a saber, tratamento psicológico específico.

A categoria mediação, central para o pensamento dialético, forneceu o pano-de-fundo teórico-metodológico para a compreensão das ações externas 
aos sujeitos, a saber, do Ministério Público, do Juiz e das equipes psicossociais que atenderem a família. A decisão judicial foi subsidiada pelo relatório psicossocial que fundamentou sua análise a partir da constatação de que o afastamento trouxe uma gama de sentimentos à família, seja pela possibilidade de a separação ser permanente, seja não revelação do abuso como fator determinante da situação que a família se encontra. Isso permitiu também analisar as inferências mediatas, entendidas como questões de silogismo das relações afetivas no seio familiar.

Dessa forma, a objetividade da legislação e ações processuais foi colocada à prova, pois as inúmeras interligações entre os aspectos do processo e os sujeitos demonstraram que a complexidade da medida não se esgota com a sugestão ou aplicação de uma ou outra ação de proteção. Essas mediações foram observadas em diversos pontos do processo e, conforme a compreensão de totalidade complexa como sendo a existência de fenômenos universais (objetivos) que em certas circunstâncias (materiais, de classe social, gênero, raça, idade, etc.) se manifestam nas subjetividades (instável, particular e complexo) (Santos et al., 2011).

Todas as ações objetivas e reações complexas discutidas acima demonstram a lucidez interpretativa existente no processo judicial que objetiva a defesa de direitos de uma infância violada. Com recomendações e sugestões claras e precisas a respeito da dinâmica sistêmica da família, o processo judicial, firmando coesão à análise técnica do setor psicossocial, permitiu que se elencassem questões para além do positivismo da lei, notadamente insuficiente para lidar com questão desta amplitude. Tem-se, dessa forma, uma medida de ambivalência necessária, pois é a partir disso que se desvelam os detalhes perdidos na formalidade ritualística de depoimentos, requisições, encaminhamentos e demais elementos da ação do Estado na vida das pessoas.

No entanto, a ideia de garantia de direitos, representada pelo Sistema de Garantia de Direitos nos eixos de defesa, promoção e controle social, se limita à atuação da Justiça não extensiva à rede de proteção social, cuja assertividade dos procedimentos para além do judiciário se pauta em haver uma tendência recalcitrante dos próprios sujeitos, que têm seus sentimentos e demandas expostos pelo judiciário e, ao mesmo tempo, sem garantias de que o trato a eles será efetivo para além dos limites da vara da infância.

Tem-se que levantar ainda que a Justiça não necessariamente considera as questões subjetivas dos sujeitos para além dos procedimentos dentro do judiciário. Fica evidente a desarticulação não apenas da rede de proteção social, o que consequentemente se coloca como entrave para o controle social das políticas de atendimento, mas também por não ensejar o movimento contrário de aproximação entre a justiça e a sociedade. Em uma palavra, a atuação do judiciário se pauta na garantia estrita do pilar de defesa dos direitos da infância, dentro do Sistema de Garantia de Direitos, mas se configura como pouco disponível ao diálogo com a sociedade no que tange à convergência de suas ações às reais e concretas necessidades dos sujeitos, o que demanda uma maior compreensão e aproximação aos pilares da promoção/prevenção e controle social para que se possa observar a Doutrina da Proteção Integral e a Prioridade Absoluta da infância efetivamente instaurada nos processos de Justiça.

\section{Referências}

Baía, P. A. D., Magalhães, C. M. C. \& Veloso, M. M. X. (2014). Caracterização do Suporte Materno na Descoberta e Revelação do Abuso Sexual Infantil. Temas em Psicologia, 22(4), 691-700. DOI: 10.9788/TP2014.4-02

Brasil (1988). Constituição da República Federativa do Brasil. Brasília: Senado Federal.

Brasil (1990). Lei n 8.069/90 de 13 de Julho de 1990. Dispõe sobre o Estatuto da Criança e do Adolescente e dá outras providências. Disponível 
em http://www.planalto.gov.br/ccivil_03/leis/ 18069.htm

Brasil (2009). Decreto $n^{0} 7.037$, de 21 de dezembro de 2009. Aprova o programa Nacional de Direitos Humanos PNDH - 3 e dá outras providências. Disponível em http://www.planalto. gov.br/ccivil_03/_Ato2007-2010/2009/Decreto/ D7037.htm

Brasil (2013). Plano nacional de enfrentamento da violência sexual contra crianças e adolescentes. Brasília: Secretaria de Direitos Humanos.

Brasil (2004). Ensino fundamental de novo anos - orientações gerais. Brasília: Ministério da Educação.

Brino, R. F. \& Williams, L. C. A. (2009). Professores como agentes de prevenção do abuso sexual infantil: detalhamento de um programa de capacitação. Em L. C. A. Williams \& E. A. C. Araújo (eds.), Prevenção do Abuso Sexual Infantil. Um Enfoque Interdisciplinar (pp. 112127). Curitiba: Juruá.

Esber, K. (2009). Autores de violência Sexual Contra Crianças e Adolescentes. Goiânia: Cânone editora.

Faleiros, V. P. \& Faleiros, E. T. S. (2006). Circuito e curtos-circuitos: atendimento, defesa e responsabilização do abuso sexual contra crianças e adolescentes. São Paulo: Veras.

Faleiros, V. P. (2010). Estado e sociedade: parcerias e práticas contra a violência sexual. Brasília: Universa.

Ferreira, L. A. M. (2012). O Ministério Público e o direito da criança à convivência familiar. Em $\mathrm{M}$. R. F. de Azambuja \& M. H. M. Ferreira (eds.), Violência Sexual Contra Crianças e Adolescentes (pp. 318-326). Porto Alegre: Artmed.

Ferreira, M. H. M. \& Azambuja, M. R. F. (2011). Introdução. Em M. R. F. de Azambuja \& M. H. M. Ferreira (eds.), Violência Sexual Contra Crianças e Adolescentes (pp. 17-21). Porto Alegre: Artmed.

Flick, U. (2009). Introdução à pesquisa qualitativa $\left(3^{\mathrm{a}}\right.$ ed.). Porto Alegre: Artmed.
Freitas, T. P. (2011). Serviço Social e Medidas Socioeducativas: $\mathrm{O}$ trabalho na perspectiva da garantia de direitos. Serviço Social e Sociedade, 6, 30-49.

Habigzang, L. F. \& Koller S. H. (2011). Intervenção psicológica para crianças e adolescentes vítimas de violência sexual. Manual de Capacitação. São Paulo: Casa do Psicólogo.

Habigzang, L. F. Ramos, M. S. \& Koller, S. H. (2011). A Revelação do Abuso Sexual: As Medidas Adotadas pela Rede de Apoio. Psicologia: Teoria e Pesquisa, 27(4), 467-473.

Hohendorff, J. V., Habigzang, L. F. \& Koller, S. H. (2015). Psicoterapia para crianças e adolescentes vítimas de violência sexual no sistema público: panorama e alternativas de atendimento. Psicologia: Ciência e Profissão, 36(1), 182-198. DOI: http://dx.doi.org/10.1590/19823703000202014

Luna, G. L. M. Ferreira, R. C. \& Vieira, L. J. E. S. (2010). Notificação de Maus-tratos em Crianças e Adolescentes por Profissionais da Equipe Saúde da Família. Ciência \& Saúde Coletiva, 15(2), 481-491. Disponível em https://www.scielosp.org/scielo.php?pi$\mathrm{d}=\mathrm{S} 1413-81232010000200025 \&$ script $=$ sci abstract\&tlng $=\mathrm{pt}$

Machado, M. T. (2003). A proteção constitucional de crianças e adolescentes e os direitos humanos. São Paulo: Manole.

Marra, M. M. \& Costa, L. F. (2016). Caracterização do Abuso Sexual em Clientela do CREAS. Revista Subjetividades, 16(2), 106-117. DOI: 10.5020/23590777.16.2.106-117

Meneses, F. F. F. Stroher, L. M. C., Setubal, C. B., Wolff, L. S. \& Costa, L. F. (2016). Intervenção Psicossocial com o Adulto Autor de Violência Sexual Intrafamiliar contra Crianças e Adolescentes. Contextos Clínicos, 9(1), 98-108. DOI: $10.4013 /$ ctc. 2016.91 .08

Minayo, M. C. S. (1993). O Desafio do Conhecimento. Pesquisa Qualitativa em Saúde ( $3^{\mathrm{a}}$ ed.). São Paulo/Rio de Janeiro: Hucitec/Abrasco. 
Minuchin, S., Nichols, M. P. \& Lee, W-Y. (2009). Família e casais. Do sintoma ao sistema. Porto Alegre: Artmed.

Oliveira, J. R., Costa, M. C. O., Amaral, M. T. R., Santos, C. A., Assis, S. G. \& Nascimento, O. C. (2014). Violência sexual e coocorrências em crianças e adolescentes: estudo das incidências ao longo de uma década. Ciência \& Saúde Coletiva, 19(3), 759-771.

Pereira, A. C. S. \& Williams, L. C. A. (2012). Dando voz a estudantes de escolas públicas sobre situações de violência escolar. Em L. F. Habigzang \& S. H. Koller (eds.), Violência Contra Crianças e Adolescentes. Teoria, pesquisa e prática (pp. 203-218). Porto Alegre: Artmed.

Pincolini, A. M. F. \& Hutz, C. S. (2014). Abusadores sexuais adultos e adolescentes no sul do Brasil: pesquisa em denúncias e sentenças judiciais. Temas em Psicologia, 22(2), 301-311. DOI: 10.9788/TP2014.2-03

Potter, L. \& Hoffmeister, M. V. (eds.) (2016). Depoimento Especial de Crianças e Adolescentes. Quando a multidisciplinaridade aproxima os olhares. Porto Alegre: Livraria do Advogado.

Rizzini, I. \& Pilotti, F. (eds.) (2009).AArte de Governar Crianças. A história das políticas sociais, da legislação e da assistência à infância no Brasil ( $2^{\mathrm{a}}$ ed.). São Paulo: Cortez.

Rizzini, I. (2008). O século perdido: raízes históricas das políticas públicas para infância no Brasil. ( $2^{\mathrm{a}}$ ed. rev.) São Paulo: Cortez.

Santos, B. R. dos S. \& Ippolito, R. (2011) Guia Escolar: identificação de sinais de abuso e exploração sexual de crianças e adolescentes. (3a. ed.) Rio de Janeiro: Seropédica.

Santos, V. A. \& Costa, L. F. (2011). A violência sexual contra crianças e adolescentes: conhecer a realidade possibilita a proteção. Estudos de Psicologia, 28(4), 529-537.

Santos, V. A., Costa, L. F. \& Silva, A. X. (2011). As medidas protetivas na perspectiva de família em situação de violência sexual. Psico, 42(1), 77-86.

Sauerbronn, S. (n. d.) Políticas Públicas e a Proteção Integral à Criança e ao Adolescente, com Enfoque no Distrito Federal. Disponível em http://www.mpdft.mp.br/portal/pdf/unidades/ promotorias/pdij/Publicacoes/Artigo_Politicas_Publicas_para_a_Infancia_Juventude.pdf

Schmickler, C. M. (2006). O protagonista do abuso sexual: sua lógica e estratégias. Chapecó/SC: Editora Argos.

Senna, S. R. C. M. \& Dessen, M. A. (2012). Contribuições das Teorias do Desenvolvimento Humano para a Concepção Contemporânea da Adolescência. Psicologia: Teoria e Pesquisa, 28(1), 101-108.

Siqueira, A. C., Zoltowski, A. P., Giordani, J. P., Otero, T. M. \& Dell'Aglio, D. D. (2010). Processo de reinserção familiar: estudo de casos de adolescentes que viveram em instituição de abrigo. Estudos de Psicologia, 15(1), 07-15.

Vertamatti, Abreu, L. C., Drezetti, J., Valenti, V. E. $\&$ Barbosa, C. P. (2013). Time elapsed between sexual aggression and arrival at the brazilian health service. Journal of Human Growth and Development, 23(1), 46-51.

Victora, C. (2016) Evidências científicas sobre a importância da primeira infância: a estratégia dos 1.000 dias. Em Congresso Nacional. Câmara dos Deputados. Centro de Estudos e Debates Estratégicos (ed.), Avanços do Marco Legal da Primeira Infância (pp. 103-117). Brasília: Edições Câmara.
Recebido: julho 30, 2015 Aprovado: abril 25, 2018 
